\title{
"We learned how to live in Pallanza"
}

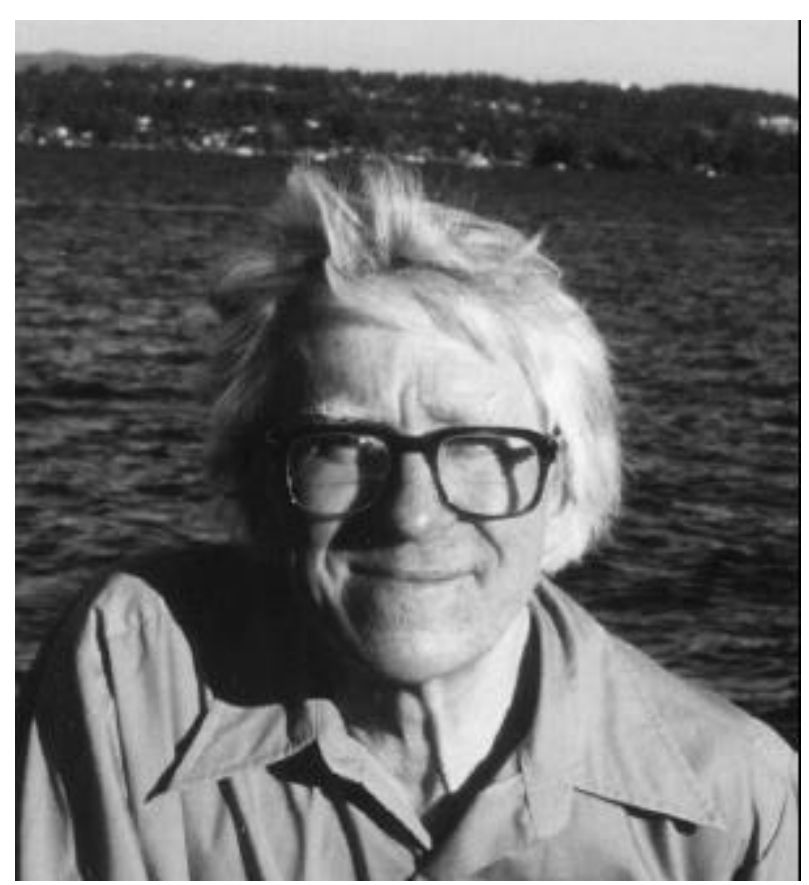

Professor W.T. Edmondson.

After months of paralysis from injuries sustained in an automobile accident, W. Thomas Edmondson died in Seattle during January. Known as "Tommy" to one and all, in keeping with his nickname he retained a youthful and alert mind until the end.

Tommy Edmondson will remain forever linked with the field of limnology that he loved. It is easy to recount his growth and accomplishments in science, starting from his first glimpse of a rotifer through the microscope he received as a gift at the age of 12 . Those fortunate to have visited with him in his Seattle office can recall fondly the sight of a desk and chair piled high with "study graphs" and various works in progress which he would graciously set aside in welcome and eager interest for the visitor. But by his own reckoning, Tommy declared that there was a moment in time that was transformational in spirit and mind. That was the period in 1959 and 1960 during which he took sabbatical leave at the great limnological centers in Windermere, Uppsala, and Pallanza. Thirty five years later, he recalled the events with earnest delight, but his fondest memories were reserved for the town on the shore of Lago Maggiore. "We learned how to live in Pallanza," was his assessment of the time.

In 1959, Edmondson had completed the editorial feat of preparing the second edition to Ward and Whipple's Freshwater Biology. Joseph Shapiro had arrived in
Seattle two years earlier and had established an effective program for nutrient chemistry measurement in Lake Washington. The transformational events in the life of that lake were at an infant stage, and Edmondson together with George Anderson and Donald Peterson had just published their first paper about the subject, "Artificial Eutrophication of Lake Washington," in the first issue of Limnology and Oceanography (Edmondson et al. 1956). His studies of the Coulee lakes in the Columbia basin of eastern Washington State had begun in 1954 , but no developments had yet reached the stage where he could not bear to be at a distance. So he took leave from Seattle with a free heart, eager to pursue an idea that had been knocking around inside his head ever since his doctoral studies with sessile rotifers.

That idea, of course, was the Egg Ratio Method for determining population birth rates of planktonic animals. Tommy had originally hatched his idea by close observation of Floscularia conifera. The cylindrical tubes built by these sessile rotifers enclose not only themselves, but their eggs as well. The eggs lined up in the tube from bottom to top, as many as seven in a row, forming a neat developmental time sequence. Each egg was a snapshot in time of egg development from oviposition to hatching; all that were missing were the time codes. Tommy solved that problem for Floscularia by an ingenious system of color coding the tubes with powdered carmine or charcoal. He perfected the way to measure birth and death rates for Floscularia populations for the second part of his doctoral dissertation, published in Ecological Monographs in 1945.

At the completion of his doctoral research, Tommy was on the brink of creating a new methodology for interpreting population dynamics of animals in nature. By analogy, he said, he was interested in methods that could be likened better to surgery than to dissection. After surgery, it should be possible to affirm that the patient was still functional. He wanted to develop a method that could measure the birth and death rates while leaving the natural populations functional. But the World War intervened, and Tommy became a physical oceanographer for the U.S. Navy, studying wave heights, marine fouling, and helping Maurice Ewing test the SOFAR zone (Lehman 1988).

By the end of the war, Tommy was eager to return to his population studies, but he would have to wait for more than a decade. In 1946 he published another paper in Ecological Monographs, this time a review of aquatic biological production, that demonstrated he already had worked out in his head the way to solve the problem for planktonic species. He proposed experimental studies of 
freshly collected eggs, reared at different temperatures, to estimate their development times. Tommy's "Factors in the dynamics of rotifer populations" was a remarkable piece of a priori predictive theory at the time of publication, but the idea lay fallow for 14 years. All the correct elements were present, birth and death rates from egg data, temperature, and population time series, expressed in terms easily recognizable to subsequent practitioners of the method. Yet without real world application to real data, the prescriptions may have seemed too cryptic to readers, and no one seized on the power of the ideas.

Tommy himself had neither the time nor adequate facilities to turn his theory into practice. Before moving to Seattle to accept a position as Assistant Professor, he had accepted the love's labor of Ward and Whipple, and that was not laid to rest until 1958. Finished at last in October of that year, he sought the freedom to pursue his long-laid plan with the help of a Senior Postdoctoral Fellowship from the U.S. National Science Foundation. Tommy would work at the Istituto Italiano di Idrobiologia in the heart of the northern Italian lake district. He would be hosted by Dr. Vittorio Tonolli, himself a legendary intellectual figure in limnology. Edmondson wrote in his application "The station at Pallanza has unusually complete temperature control equipment in which aliquots from uniform batches of eggs could be placed for an exact determination of the influence of temperature on the rate of development. It also has available lakes in which a wide variety of material could be collected during the summer, fall, and winter."

Vittorio Tonolli and his wife Livia graciously extended to Tommy and Yvette the use of living quarters within the Institute building. The Edmondsons were intentionally given room number 7 , as insurance for a successful visit. Vittorio took pride in the modern facilities and excellent technical capabilities of his institute, and he made sure that no obstacles would prevent a successful project. Three chambers with controlled temperature were placed at Edmondson's disposal, excellent devices that maintained temperature to within $0.2{ }^{\circ} \mathrm{C}$ of the selected value. With these, Edmondson could incubate the eggs of isolated females from laying to hatching.

The proximity of Room 7 to the laboratory with its temperature chambers and microscopes made it possible to continue the observations both day and night, sometimes barely interrupting slumber. The week of each experiment was grueling, but the marathon sessions were interspersed with trips to Milan for concerts, with a visit to the Marine Station at Naples, visits to other limnology laboratories, and picnic excursions into the Italian Alps. It was a time of total immersion in work mingled with deep immersion in culture and congeniality. Everything was interesting.

Tommy abbreviated his planned visit to Uppsala, and altered his work plans at Windermere, so that he could return to Pallanza for additional time at the end of his fellowship period. He bundled his development rate results into a great opus for publication in the bulletin of the Italian Institute during 1960. In addition to the development rate experiments, he included a practical application of the egg ratio method to existing field data. He showed by example how egg ratios and water temperatures were used to construct birth rates for different rotifer species, and how comparisons with observed rates of population increase or decrease reveal the prevailing death rates.

Future extensions of the Egg Ratio Method were anticipated in the Memorie paper: "The egg ratio method appears to be applicable to any animal which carries its eggs or deposits them in such a way that they can be sampled quantitatively, and for which usable rates of development can be measured."

Edmondson's communication in the Memorie volume of 1960 was an especially effective publication. It possessed every key element that might entice readers and potential students to the problem. The conceptual basis was articulated in plain language and in simple mathematical formulations that made explicit predictions from defined measurements. It presented an experimental methodology and showed how to collect and interpret data needed for quantitative predictions. Finally, it applied both theory and measurements to a case in nature where the results made a great deal of sense. But it had another feature that made it a magnet for inspired followers: there was a place for expansion in the details.

What Edmondson accomplished with his 1960 paper was analogous to the artistic achievement of a da Vinci outlining The Battle of Anghiari in masterpiece mural dimensions. The scene was a breathtaking range of landscape dimension in proper perspective, with enough focus and characters placed in commanding view as to stir the mind. But there was a lot that still needed to be filled in, and it was not apparent how all the details would work out, or exactly how the eye would flow from point to point in close inspection. The big picture was inspiring, and there were many projects of definable scope within it. Most importantly, there was enough already sketched out to point the way, but not to hamstring it, and the techniques were such that anyone with basic skills, equipment, and access to biological material could join in without exclusion.

The Egg Ratio Method was a wonderful gift to limnologists, because it placed in the hands of zooplankton biologists a tool as powerful and enlightening as the Light and Dark Bottle Method for measuring primary biological production. The method was adopted quickly and became the tool of choice in demonstrating death rate variations. It arguably helped to foster the period of explosive growth in zooplankton ecology in the decades that followed. Edmondson understood that the right 
method was a key to scientific progress: "Given brains, the creation of ideas is limited by information. The creation of information is limited by methods" (Edmondson 1990, p. 336).

Both Tommy and Yvette cherished Pallanza, and they counted their enlightened days of life as beginning with their visit. It held a magic for them that would not be equaled. Tommy never took another sabbatical leave, and he and Yvette were never comfortable travelers away from their beautiful home perched on a bluff overlooking Lake Washington. But Italy was their passion, and Pallanza was regarded in reverence as a sanctuary (Edmondson \& Edmondson 1990). Memories so vivid and perfect sometimes need to remain unchallenged by repetition, so as not to dilute their spiritual power.

John T. Lehman

Department of Biology and Center for Great Lakes and Aquatic Sciences

University of Michigan, Ann Arbor, Michigan

\section{REFERENCES}

Edmondson, W.T. 1945. Ecological studies of sessile Rotatoria. Part II. Dynamics of populations and social structures. Ecol. Monogr., 15: 141-172.

Edmondson, W.T. 1946. Factors in the dynamics of rotifer populations. Ecol. Monogr., 16: 357-372.

Edmondson, W.T., G.C. Anderson \& D.R. Peterson 1956. Artificial eutrophication of Lake Washington. Limnol. Oceanogr., 1: 47-53.

Edmondson, W.T. 1959. Ward and Whipple's Freshwater Biology. Editor of second edition; author of Preface, Introduction, and Chapters on Rotifers and Methods. Wiley.

Edmondson, W.T. 1960. Reproductive rate of rotifers in natural populations. Mem. Ist. ital. Idrobiol., 12: 21-77.

Edmondson, W.T. 1990. Perspectives on plankton studies. Mem. Ist. ital. Idrobiol., 47: 331-361.

Edmondson, W.T. \& Y.H. Edmondson. 1990. Pallanza as a haven for visiting limnologists. Mem. Ist. ital. Idrobiol., 47: 45-55.

Lehman, J.T. 1988. Good Professor Edmondson. Limnol. Oceanogr., 33: 1236-1246. 